\title{
Editorial Expression of Concern: Trajectory tracking system of wheeled robot based on immune algorithm and sliding mode variable structure
}

Yanting $\operatorname{Lan}^{1} \cdot$ Xiaodong Chen ${ }^{2}$

Published online: 6 December 2021

(c) Springer-Verlag GmbH Germany, part of Springer Nature 2021

\section{Expression of concern to: Intelligent Service Robotics https://doi.org/10.1007/s11370-020-00325-8}

The Editor-in-Chief would like to alert the readers that the peer review process of this article may have been compromised. Post-publication peer review did not identify any major flaws in the article, but suggested minor revisions. The authors did not provide any comments or corrections. Therefore, the readers are advised to interpret the results with caution.

\begin{abstract}
Authors Yanting Lan and Xiaodong Chen have not responded to any correspondence from the editor or publisher about this Editorial Expression of Concern.
\end{abstract}

Publisher's Note Springer Nature remains neutral with regard to jurisdictional claims in published maps and institutional affiliations.

The original article can be found online at https://doi.org/10.1007/ s11370-020-00325-8.

Yanting Lan

lytcyb@foxmail.com

1 School of Electrical and Control Engineering, North University of China, Taiyuan, China

2 College of Agronomy, China Agricultural University, Beijing, China 